\title{
Maternal serum concentrations of insulin-like growth factor (IGF)-I and IGF binding protein-1 before and during pregnancy in relation to maternal body weight and composition and infant birth weight
}

\author{
Hanna Olausson ${ }^{1,2} *$, Marie Löf ${ }^{1}$, Kerstin Brismar $^{3}$, Elisabet Forsum ${ }^{1}$ and Annica Sohlström ${ }^{1}$ \\ ${ }^{1}$ Division of Nutrition, Department of Clinical and Experimental Medicine, Linköping University, SE-581 85 Linköping, Sweden \\ ${ }^{2}$ Department of Clinical Nutrition, University of Gothenburg, Sahlgrenska Academy, Box 459, SE-405 30 Göteborg, Sweden \\ ${ }^{3}$ Unit of Endocrinology and Diabetology, Department of Molecular Medicine and Surgery, Karolinska Institutet, \\ Rolf Luft Center for Diabetes Research, Karolinska University Hospital, Stockholm, Sweden
}

(Received 17 June 2009 - Revised 8 December 2009 - Accepted 4 January 2010 - First published online 11 May 2010)

Maternal nutritional status, e.g. body weight and composition, is associated with fetal growth. It has been suggested that the insulin-like growth factor (IGF) system may be a mediator of this relationship. In twenty-three healthy Swedish women, we studied (1) the relationships before and during pregnancy between maternal serum concentrations of IGF-I and IGF binding protein-1 (IGFBP-1) and maternal body weight and composition; (2) interactions between serum concentrations of IGF-I (before and in early pregnancy) and maternal nutritional status in relation to infant birth weight. We found that serum IGF-I during pregnancy was positively correlated with maternal body weight $(r 0.47-0 \cdot 56)$ and fat-free body weight $(r$ 0.61-0.65), whereas serum IGFBP-1 was negatively correlated with maternal body weight $(r-0.44$ to -0.69$)$ and body fat $(r-0.64$ to -0.76$)$ before and during pregnancy. Women with a lower body fat content $(\%)$ before pregnancy had greater increases in serum IGFBP-1 during pregnancy than women with a higher prepregnant body fat content $(\%)$. In addition, significant fractions of the variation in corrected infant birth weight were explained by variables related to the maternal nutritional status when these were combined with serum concentrations of IGF-I in gestational week 14 (adjusted $r^{2} 0 \cdot 25-0.44, P=0.001-0.021$ ), but not when they were combined with such concentrations before pregnancy (adjusted $r^{2} 0 \cdot 11-0 \cdot 12, P=0 \cdot 105-0 \cdot 121$ ). These results suggest mechanisms by which the IGF system may be a mediator between maternal nutritional status and fetal growth.

Insulin-like growth factor-I: Insulin-like growth factor binding protein-1: Body fat: Fat-free body weight: Infant birth weight

The association between maternal nutritional status and fetal growth is well known. For example, the weight, BMI and fat content of the maternal body correlate positively with infant birth weight ${ }^{(1,2)}$. The maternal insulin-like growth factor (IGF) system has been suggested to be a mediator between maternal nutritional status and fetal growth ${ }^{(3)}$, because it is affected by nutritional status ${ }^{(4)}$ and influences placental development, function and nutrient transfer ${ }^{(5,6)}$, as well as maternal retention of nutrients ${ }^{(7)}$. This system includes the ligands IGF-I and IGF-II (IGF) and six binding proteins (IGF binding protein (IGFBP)-1-6). Free IGF have either immediate anabolic insulin-like effects on protein and carbohydrate metabolism or long-term effects on cell replication and differentiation ${ }^{(8)}$. In the circulation, most IGF are bound to binding proteins. This provides a mechanism to regulate the biological activity of the free IGF. Binding protein IGFBP-3 binds $80-90 \%$ of all IGF in serum. However, during pregnancy, proteases degrade IGFBP- $3^{(9-12)}$, which decreases its affinity for IGF. This may increase the metabolic action of IGF-I on target cells such as those in the placenta, possibly stimulating fetal growth. IGFBP-1 binds only about $2 \%$ of serum $\operatorname{IGF}^{(13)}$, but it is important for the short-term regulation of IGF activity, and has a role in blood glucose regulation $^{(14)}$.

Reports of relationships between serum concentrations of IGF-I in pregnant women and birth weight of their babies are contradictory as some studies ${ }^{(15-18)}$, but not all ${ }^{(19)}$, have shown such relationships to be positively significant. In a previous study on healthy, pregnant, Swedish women, we found serum concentrations of IGF-I to be significantly correlated with fetal weight in the third trimester ${ }^{(12)}$. In these women, we also observed a decrease in the serum concentration of IGF-I in the very beginning of pregnancy. Women with a high concentration before pregnancy had a more pronounced decrease in this concentration than women with a low concentration before pregnancy ${ }^{(12)}$. Furthermore, we identified significant negative correlations between the maternal serum concentration of IGFBP-1 in gestational weeks 20,32 and 35 and birth weight of infants ${ }^{(12)}$. A few studies have investigated relationships in pregnant and

Abbreviations: IGF, insulin-like growth factor; IGFBP, IGF binding protein.

* Corresponding author: Hanna Olausson, fax +46 31 7863101, email hanna.olausson@gu.se 
non-pregnant women between serum concentrations of IGF-I and IGFBP-1 and body weight, BMI or body composition. In non-pregnant women of reproductive age, the results are contradictory $^{(20-22)}$. Thus, Jernström \& Olsson ${ }^{(21)}$ reported a positive correlation between IGF-I serum concentrations and body weight, whereas others have reported that such concentrations are unrelated to body fat ${ }^{(22)}$ and $\mathrm{BMI}^{(20)}$. In pregnant women, Hills et al. $^{(19)}$ reported a significant positive relationship between serum IGF-I and body weight. Comparable studies for IGFBP-1 demonstrate that the serum concentration of this protein is negatively related to body weight, BMI and/or the body fat content of women before ${ }^{(22)}$ as well as during pregnancy ${ }^{(19,23,24)}$. However, to understand whether the maternal IGF system represents a mediator between maternal nutritional status and fetal growth, further studies of the relationships between serum concentrations of IGF-I and IGFBP-1 and nutritional status in terms of body weight and composition are needed in women.

Our previous study in healthy Swedish women included longitudinal assessments, before and during pregnancy, of an extensive set of variables including components of the IGF system as well as accurate measures of body composition. This dataset has been used in a number of studies on pregnancy in relation to, for example, energy metabolism ${ }^{(25,26)}$, body composition ${ }^{(26-28)}$ and serum concentrations of hormones $^{(25,29)}$, including the IGF system ${ }^{(12)}$. In the present study, we took advantage of the longitudinal design when testing the hypothesis that the maternal IGF system may act as a mediator between maternal nutritional status and fetal growth. This was carried out, first, by investigating relationships, before and during pregnancy, between maternal serum concentrations of IGF-I and IGFBP-1 and maternal body weight and composition. In addition, we explored how concentrations of IGF-I, before and in early pregnancy, may impact infant birth weight when combined with maternal body weight and composition.

\section{Subjects and methods}

\section{Subjects}

Thirty-nine women planning pregnancy were recruited via the health care system or via advertisements in a local newspaper in the city of Linköping. Twenty-three of these became pregnant and completed the study. The women were all healthy non-smokers with no eating disorders and with a BMI before conception ranging from 18 to 39 . Before pregnancy, the women had normal concentrations of blood glucose and serum insulin, and none was diagnosed with gestational diabetes $^{(12)}$. Data regarding their serum insulin concentrations and insulin resistance before and during pregnancy have been published previously ${ }^{(29)}$. Relevant data regarding the women and their infants are given in Table 1. Body weight and composition of the women before and during pregnancy have been described previously ${ }^{(26)}$. Infant birth weight and serum IGF-I and IGFBP-1 data have been reported by Olausson et al. ${ }^{(12)}$. Each woman delivered one healthy infant after 280 (SD 10; range 256-296) d of pregnancy. At birth, the infants weighed 3740 (SD 510; range 2600-4540) g and were 51 (SD 2; range 46-57) cm long.

\section{Study outline}

The measurements were done before conception and at weeks 14 and 32 of pregnancy. Women arrived early in the morning after an overnight fast for measurements of body weight, blood collection and administration of a dose of ${ }^{2} \mathrm{H}$. Stage of gestation was assessed using ultrasound, generally at weeks $12-14^{(30)}$. Infant body weight and length were measured just after delivery. The study was conducted according to the guidelines laid down in the Declaration of Helsinki, and all procedures involving human subjects were approved by the Research Ethics Committee of the University of Linköping, Sweden. Verbal informed consent, witnessed and formally recorded, was obtained from all subjects.

\section{Body composition and anthropometry}

Women. Body weight was recorded using a digital balance (KCC150; Mettler-Toledo, Albstadt, Germany). Fat-free body weight was calculated from total body water estimated using ${ }^{2} \mathrm{H}$ dilution as described previously ${ }^{(27)}$. Total body water was divided by the appropriate hydration fraction (before pregnancy, 0.718; week 14, 0.722; and week 32, 0.747 ) to assess fat-free body weight ${ }^{(27)}$. Body fat was calculated as body weight minus fat-free body weight.

Infants. Body weight was recorded using an electronic column scale, and length using a length board. These measurements were obtained from hospital records. Corrected infant birth weight, to account for differences in birth weight due to gestational age and sex, was calculated as recorded birth weight times the ratio of recorded birth weight and mean

Table 1. Characteristics of women before pregnancy and in gestational weeks 14 and 32

(Mean values, standard deviations and ranges, $n$ 23)

\begin{tabular}{|c|c|c|c|c|c|c|c|c|c|}
\hline \multirow[b]{2}{*}{ Women } & \multicolumn{3}{|c|}{ Before pregnancy } & \multicolumn{3}{|c|}{ Week 14} & \multicolumn{3}{|c|}{ Week 32} \\
\hline & Mean & SD & Range & Mean & SD & Range & Mean & SD & Range \\
\hline Body weight (kg) & $67 \cdot 3$ & $12 \cdot 6$ & $51 \cdot 0-95.0$ & $69 \cdot 7$ & $12 \cdot 6$ & $51 \cdot 9-95 \cdot 4$ & $79 \cdot 1$ & $13 \cdot 0$ & $58 \cdot 3-101 \cdot 2$ \\
\hline Fat-free body weight (kg) & 44.6 & $5 \cdot 5$ & $35 \cdot 3-52 \cdot 9$ & $45 \cdot 7$ & $6 \cdot 0$ & $36 \cdot 2-55 \cdot 5$ & $52 \cdot 2$ & 5.9 & $41 \cdot 2-60 \cdot 6$ \\
\hline Body fat (\%) & $32 \cdot 6$ & $7 \cdot 8$ & $17 \cdot 2-49 \cdot 8$ & 33.5 & $7 \cdot 1$ & $23 \cdot 0-51 \cdot 3$ & 33.3 & $7 \cdot 3$ & $16 \cdot 9-47 \cdot 8$ \\
\hline Body fat (kg) & $22 \cdot 6$ & 8.9 & $8 \cdot 9-43 \cdot 1$ & $24 \cdot 0$ & 8.9 & $12 \cdot 6-46 \cdot 0$ & $27 \cdot 0$ & 9.5 & $11 \cdot 3-46 \cdot 0$ \\
\hline IGF-I ( $\mu \mathrm{g} / \mathrm{l})$ & 273 & 90 & $150-460$ & 183 & 45 & $87-262$ & 391 & 148 & $193-709$ \\
\hline IGFBP-1 ( $\mu \mathrm{g} / \mathrm{l})$ & 21 & 12 & $7-56$ & 145 & 61 & $57-296$ & 140 & 59 & $42-268$ \\
\hline
\end{tabular}

IGF-I, insulin-like growth factor-I; IGFBP-1, IGF binding protein-1. 
birth weight of healthy Swedish newborns with the appropriate gestational age and $\operatorname{sex}^{(31)}$.

\section{Analyses of blood samples}

Blood was collected by cubital vein puncture. Samples were kept at $+4^{\circ} \mathrm{C}$ for a maximum of $4 \mathrm{~h}$ before being centrifuged at $1500 \mathrm{~g}$ for $10 \mathrm{~min}$. Serum was harvested and stored at $-70^{\circ} \mathrm{C}$. Total IGF-I in serum was measured using RIA after acid-ethanol extraction ${ }^{(32)}$. The intra-assay CV were $4.3 \%$ at $149 \mu \mathrm{g} / \mathrm{l}$ and $8.6 \%$ at $526 \mu \mathrm{g} / \mathrm{l}$, while the inter-assay $\mathrm{CV}$ was $11 \%$. IGFBP-1 was analysed using RIA as described by Póvoa et al. ${ }^{(33)}$. The intra-assay CV were $8.4 \%$ at $18 \mu \mathrm{g} / 1$ and $6.0 \%$ at $90 \mu \mathrm{g} / \mathrm{l}$. The inter-assay $\mathrm{CV}$ was $10 \%$.

\section{Statistical analyses}

Results presented are means and standard deviations. Simple linear regression and correlation analyses were used. To identify significant differences between slopes of regression lines, we evaluated whether there was an interaction between an independent variable and stage of gestation in the effect on the dependent variable. This evaluation was carried out using multiple regression analysis including an interaction term between the independent variable and stage of gestation. Multiple regression analysis was also used to explore how corrected infant birth weight varied in response to two independent variables (serum IGF-I concentration in combination with body weight and body fat). $P \leq 0.05$ was considered statistically significant. Statistical analyses were carried out using Statistica 6.1 (StatSoft, Inc., Tulsa, OK, USA) and SPSS (version 6.0; Chicago, IL, USA).

\section{Results}

Serum concentrations of insulin-like growth factor-I and insulin-like growth factor binding protein-1 in relation to maternal body weight and composition

Correlation coefficients for relationships between serum concentrations of IGF-I and variables describing body weight and composition are given in Table 2. Before pregnancy, no correlations were found between serum IGF-I and body weight, body fat ( $\mathrm{kg}$ and \%) or fat-free body weight $(\mathrm{kg})$. However, in gestational weeks 14 and 32, significant positive correlations with serum IGF-I were found for body weight and fat-free body weight, while body fat $(\mathrm{kg}$ and \%) was not correlated with serum IGF-I on these measurements. Table 2 also shows the corresponding correlations for serum concentrations of IGFBP-1. Before pregnancy and in gestational weeks 14 and 32 , serum concentrations of IGFBP-1 were significantly correlated with body weight and body fat ( $\mathrm{kg}$ and \%), but not with fat-free body weight. Fig. 1 shows the regression lines obtained when IGFBP-1 in serum is regressed on body fat $(\%)$ in gestational week 14 and before pregnancy (Fig. 1(a)) and on body fat (\%) in gestational week 32 and before pregnancy (Fig. 1(b)). The slope of the regression line obtained before pregnancy was significantly different from the corresponding value obtained in gestational week $14(P=0.0001)$ as well as from the corresponding value obtained in gestational week $32(P=0.0001)$. In addition,
Table 2. Correlation coefficients $(r)$ and their probabilities $(P)$ for linear relationships obtained when serum concentrations of insulin-like growth factor-I (IGF-I) or IGF binding protein-1 (IGFBP-1) are regressed on body weight, body fat and fat-free body weight, respectively*

\begin{tabular}{|c|c|c|c|c|}
\hline & \multicolumn{2}{|c|}{ IGF-I ( $\mu \mathrm{g} / \mathrm{I})$} & \multicolumn{2}{|c|}{ IGFBP-1 ( $\mu \mathrm{g} / \mathrm{l})$} \\
\hline & $r$ & $P$ & $r$ & $P$ \\
\hline \multicolumn{5}{|l|}{ Before pregnancy } \\
\hline Body weight $(\mathrm{kg})$ & 0.08 & $>0.05$ & -0.44 & 0.033 \\
\hline Body fat $(\mathrm{kg})$ & -0.08 & $>0.05$ & -0.64 & 0.001 \\
\hline Body fat (\%) & -0.20 & $>0.05$ & -0.72 & 0.0001 \\
\hline Fat-free body weight $(\mathrm{kg})$ & 0.29 & $>0.05$ & 0.08 & $>0.05$ \\
\hline \multicolumn{5}{|l|}{ Gestational week 14} \\
\hline Body weight $(\mathrm{kg})$ & 0.56 & 0.005 & -0.63 & 0.001 \\
\hline Body fat $(\mathrm{kg})$ & 0.36 & $>0.05$ & -0.70 & 0.0002 \\
\hline Body fat (\%) & 0.11 & $>0.05$ & -0.69 & 0.0002 \\
\hline Fat-free body weight $(\mathrm{kg})$ & 0.65 & 0.001 & -0.30 & $>0.05$ \\
\hline \multicolumn{5}{|l|}{ Gestational week 32} \\
\hline Body weight $(\mathrm{kg})$ & 0.47 & 0.024 & -0.69 & 0.0003 \\
\hline Body fat $(\mathrm{kg})$ & 0.27 & $>0.05$ & -0.76 & 0.00003 \\
\hline Body fat (\%) & 0.07 & $>0.05$ & -0.74 & 0.00005 \\
\hline Fat-free body weight $(\mathrm{kg})$ & 0.61 & 0.002 & -0.30 & $>0.05$ \\
\hline
\end{tabular}

* Results were obtained from twenty-three healthy women before pregnancy and in gestational weeks 14 and 32 .

Fig. 2 illustrates the relationships obtained when the serum concentrations of IGFBP-1 during pregnancy minus the corresponding values obtained before pregnancy were regressed on body fat $(\%)$ before pregnancy. These regression lines were significant with negative slopes when values in gestational week 14 (a) as well as in gestational week 32 (b) were used.
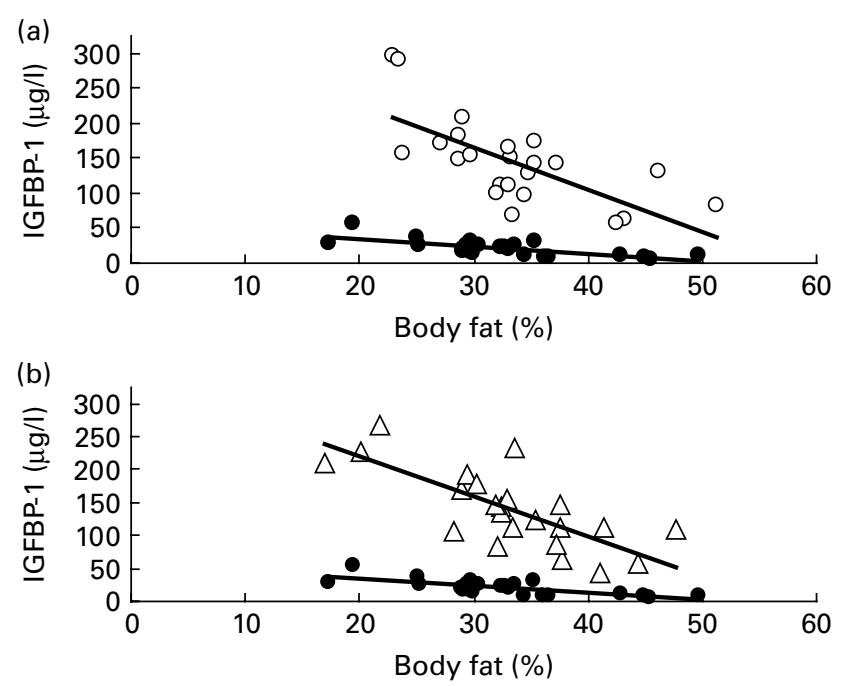

Fig. 1. Serum concentration of insulin-like growth factor binding protein-1 $($ IGFBP-1; $\mu \mathrm{g} / \mathrm{l})(y)$ regressed on body fat $(\%)(x)(a)$ before pregnancy $(\bullet)$ and in gestational week $14(O ; n 23)$, and (b) before pregnancy $(\bullet)$ and in gestational week $32(\triangle ; n$ 23). Regression equations are as follows: $y=56.4-1.1 x, r-0.720, P=0.0001$ (before pregnancy); $y=346.0-6.0 \dagger x$, $r-0.693, P=0.0002$ (gestational week 14); $y=333.8-6.0 \dagger x, r-0.743$, $P=0.00005$ (gestational week 32). †The slope of the regression line was significantly different from the corresponding value before pregnancy assessed after identification of an interaction between body fat (\%) and stage of gestation in the effect on the serum concentration of IGFBP-1 $(P=0.0001)$. This assessment was made by means of multiple regression analysis, where an interaction term between body fat (\%) and stage of gestation was included. 

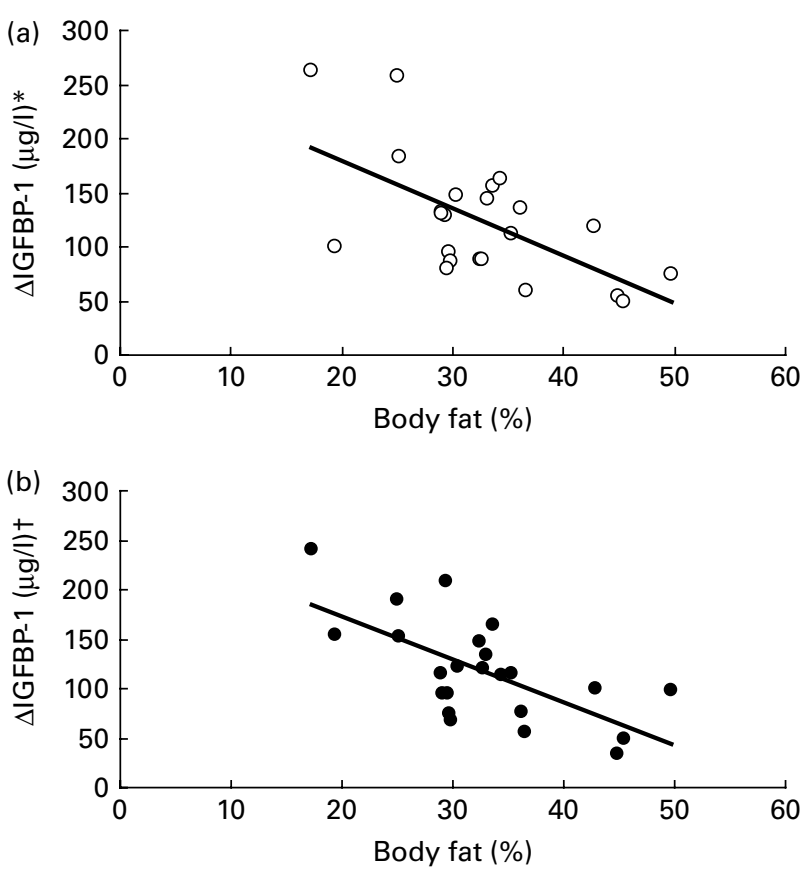

Fig. 2. Difference in insulin-like growth factor binding protein-1 ( $\triangle$ IGFBP-1) serum concentrations $(\mu \mathrm{g} / \mathrm{l})(y)(\mathrm{a})$ between values obtained in gestational week 14 and before pregnancy ( $n$ 23), and (b) between values obtained in gestational week 32 and before pregnancy $(n 23)$ regressed on body fat $(\%)$ before pregnancy $(x)$. Regression equations are as follows: (a) $y=267-4.4 x, r-0.613, P=0.002$; (b) $y=260-4.3 x, r-0.664$ $P=0.001$. ${ }^{*} \Delta$ IGFBP-1: the serum concentration in gestational week 14 minus the corresponding concentration before pregnancy. $\dagger \Delta$ IGFBP-1: the serum concentration in gestational week 32 minus the corresponding concentration before pregnancy.

Serum concentrations of insulin-like growth factor-I before pregnancy and in gestational week 14 and maternal body weight and composition in relation to corrected infant birth weight

Both maternal body weight $(\mathrm{kg})$ and body fat content $(\mathrm{kg})$ before pregnancy were significantly correlated with corrected infant birth weight $(r 0.436, P=0.038$ and $r 0.443, P=0.034$, respectively). Similarly, in gestational week 14 , significant correlations were observed between maternal body weight $(\mathrm{kg})$ and corrected infant birth weight $(r 0.449, P=0.032)$, as well as between the body fat content $(\mathrm{kg})$ and corrected infant birth weight $(r 0.438, P=0.037)$. No significant correlations were observed between serum IGF-I $(\mu \mathrm{g} / \mathrm{ml})$ and corrected infant birth weight either before pregnancy $(r 0 \cdot 015$, $P=0.947)$ or in gestational week $14(r-0.174, P=0.428)$.

Table 3 shows adjusted $r^{2}$ for multiple linear relationships relating corrected infant birth weight $(y)$ to two independent variables, including the serum concentration of IGF-I (either before pregnancy or in gestational week 14) and either maternal body weight or body fat content (before pregnancy or in gestational week 14). Combinations including IGF-I in gestational week 14 explained significant $(P=0 \cdot 001-0 \cdot 021)$ fractions of the variation in corrected infant birth weight (adjusted $\left.r^{2} 0.251-0.435\right)$, while combinations including IGF-I before pregnancy did not explain any significant $(P=0 \cdot 105-0 \cdot 121)$ fraction of this variation (adjusted $\left.r^{2} 0 \cdot 109-0 \cdot 122\right)$. Fig. 3 shows a graphical representation of two of the relationships given in Table 3. These relationships

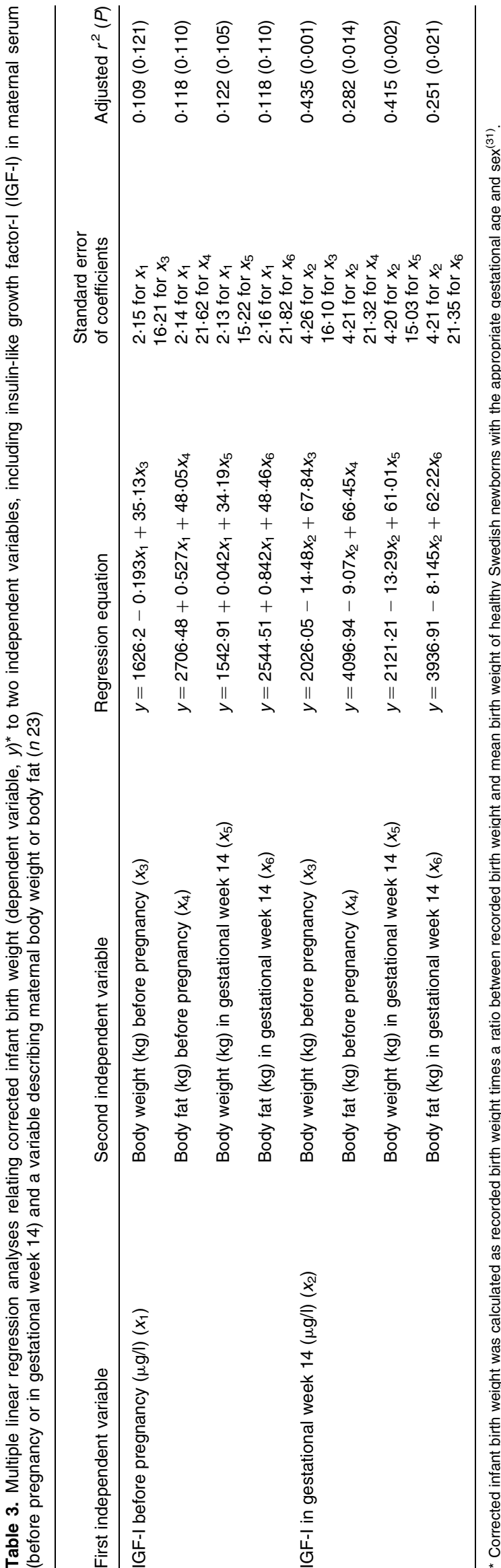



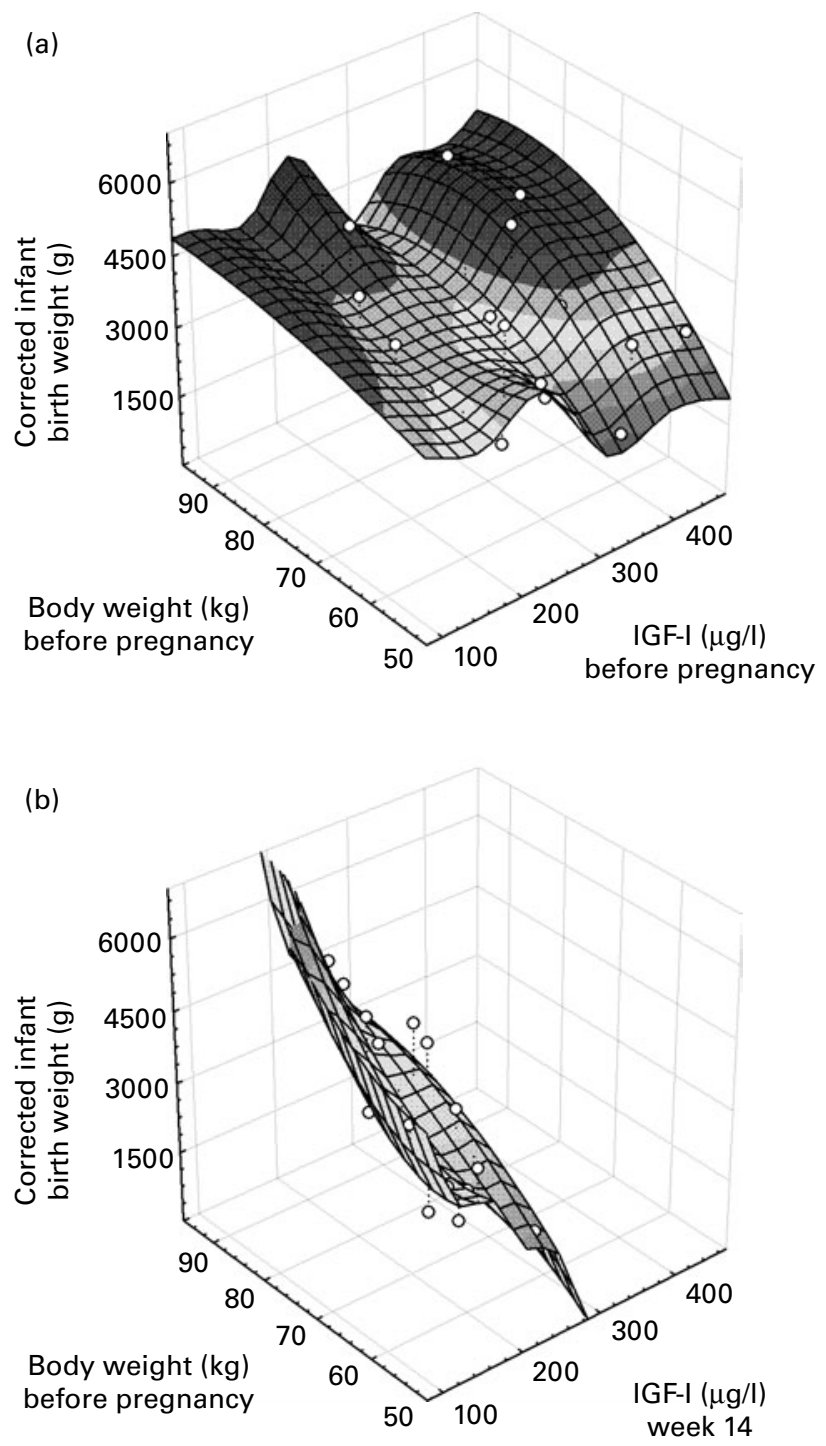

Fig. 3. A graphical representation of the relationships between corrected infant birth weight $(\mathrm{g})$ (dependent variable) and the maternal serum concentration of insulin-like growth factor-1 (IGF-I; $\mu \mathrm{g} / \mathrm{l}$ ) (first independent variable) before pregnancy (a) or in gestational week 14 (b), and maternal body weight $(\mathrm{kg})$ before pregnancy (second independent variable). Regression equations are given in Table 3.

show the effect on corrected infant birth weight of using the serum concentration of IGF-I before pregnancy (a) $v$. in gestational week 14 (b) as one of the two independent variables when body weight before pregnancy was the second independent variable.

\section{Discussion}

In a previous paper ${ }^{(28)}$ based on the dataset that was the same as that used in the present study, we reported relationships between maternal body weight and composition and infant birth weight. In the present paper, we investigated whether the maternal IGF system has a role in mediating the kind of relationships observed in our previous study ${ }^{(28)}$. Our dataset provided a unique opportunity to investigate this area for the following reasons: it has a longitudinal design and includes measurements before conception and in early pregnancy, as well as information on infant birth weight. Furthermore, our body composition results are based on assessments of total body water using ${ }^{2} \mathrm{H}$ dilution and application of appropriate hydration factors, a procedure known to result in accurate estimates of body fat. A combination of these accurate and longitudinal data, thus, provided a unique opportunity to study interactions between maternal body weight and composition, the maternal IGF system and infant birth weight.

An intriguing observation is that the serum IGF-I concentration becomes correlated with maternal body weight and fat-free body weight after the serum concentration of IGF-I decreases during the first part of pregnancy. In addition, the multiple regression models presented in Table 3 and Fig. 3 suggest that lower concentrations of IGF-I in early pregnancy are favourable for fetal growth when combined with maternal body weight or fat content. A possible interpretation is that a regulatory activity is involved, originating in the product of conception with the purpose of controlling growth of the maternal body. Early pregnancy represents a period of balance between anabolism and catabolism, and it is important for the fetus that growth of the maternal body is maintained within appropriate limits. A certain proliferation of the maternal body is advantageous for the fetus, but if this growth becomes excessive, the fetus may be unable to compete successfully for available nutrients. It should be pointed out, however, that this interpretation certainly is speculative and requires confirmation. In this context, it is also relevant to note that an experimental study in animals has shown that maternal circulating concentrations of IGF-I from early gestation to mid-gestation may impact fetal growth and placental transport near term ${ }^{(5)}$.

Figs. 1 and 2 show that women with a low body fat content before pregnancy have higher increases during pregnancy in their serum concentrations of IGFBP-1 than women with a high body fat content before pregnancy. This is noteworthy since high serum concentrations of IGFBP-1 during the second half of pregnancy are associated with low birth weight $^{(12)}$, and therefore also with slow fetal growth. This suggests the presence of a regulatory process responsible for maintaining a fetal growth rate appropriate to the nutritional status of the mother. It is possible that low serum concentrations of IGFBP-1 result in higher concentrations of free IGF-I, with the possible consequence being a stimulating effect on fetal growth via the stimulating actions of free IGF-I on the placenta. However, it is unlikely that this mechanism explains more than a part of the relationship between maternal serum IGFBP-1 concentrations and fetal growth rate since IGFBP- 1 binds only about $2 \%$ of all IGF-I. Insulin and blood glucose also influence serum concentrations of IGFBP-1 ${ }^{(14)}$, and therefore it is possible that the observed relationship between serum IGFBP-1 and fetal growth is due to the glucoregulatory effects of IGFBP-1 and its relationship to insulin. However, in our women, neither serum concentrations of insulin nor insulin resistance ${ }^{(29)}$ was significantly correlated with corrected birth weight of their infants. In this context, it may be relevant to note that in our women, serum concentrations of insulin and insulin resistance were significantly correlated with body fat $(\%)^{(29)}$. Insulin resistance during pregnancy is thought to promote fetal growth, since women with gestational diabetes tend to deliver infants with high birth weight ${ }^{(34)}$. The mechanism behind the 
enhanced fetal growth is thought to be increased exposure to all major fuel sources i.e. glucose, NEFA and amino acids ${ }^{(35)}$. Franks et al. ${ }^{(36)}$ recently reported that blood glucose concentrations are related to infant birth weight also in nondiabetic pregnant women. Hence, it is possible that the mechanisms explaining the relationships found in the present study regarding serum concentrations of IGFBP-1, the maternal body fat content and corrected infant birth weight are related to interactions between insulin, blood glucose and IGFBP-1.

One weakness of the present study is the small number of women studied. It is noteworthy, however, that their BMI before pregnancy and weight gain during pregnancy are quite typical for Swedish women of childbearing age, and our women are similar to many other such women in the Western countries. A potential problem with our small sample size is the risk for type II errors, e.g. a failure to identify existing relationships as significant. Using a simple linear regression model with twenty-three observations gives a power of $80 \%$ to identify a correlation coefficient of 0.55 as significant. All relationships identified as non-significant in Table 2 have correlation coefficients well below 0.55. This is also true for correlation coefficients obtained for the relationships between corrected infant birth weight and serum concentrations of IGF-I before pregnancy and in gestational week 14 .

In conclusion, we have reported findings confirming and extending the statement that the IGF system has a role in mediating the effect of the maternal nutritional status on fetal growth. The present results provide new aspects on this role of the IGF system, and suggest that the mechanisms involved are complicated and interact in an intricate way. Studies in populations of pregnant women with different nutritional status may be valuable for increasing our understanding regarding the role of the IGF system in fetal growth regulation.

\section{Acknowledgements}

The study was funded by the Family Erling-Persson Foundation, the General Maternity Hospital Foundation, Lions Forskningsfond mot folksjukdomar, the Magnus Bergvalls Foundation, the Swedish Research Council project nos 04224, 12172 and 15402, the Swedish Society of Medicine and the Swedish Nutrition Foundation. The authors thank all the women and their infants for their participation, and acknowledge Elisabeth Norén-Krog for skilful laboratory work. The authors' responsibilities are as follows: E. F. designed the study; M. L. and H. O. conducted the study; K. B. was responsible for the hormone analyses; H. O., E. F. and A. S. analysed the data, interpreted the results and drafted the manuscript, which was reviewed by the other authors. None of the authors has a conflict of interest.

\section{References}

1. Butte NF, Ellis KJ, Wong WW, et al. (2003) Composition of gestational weight gain impacts maternal fat retention and infant birth weight. Am J Obstet Gynecol 189, 1423-1432.

2. Baker JL, Michaelsen KF, Rasmussen KM, et al. (2004) Maternal prepregnant body mass index, duration of breastfeeding, and timing of complementary food introduction are associated with infant weight gain. Am J Clin Nutr 80, 1579-1588.

3. Owens JA (1991) Endocrine and substrate control of fetal growth: placental and maternal influences and insulin-like growth factors. Reprod Fertil Dev 3, 501-517.

4. Thissen JP, Ketelslegers JM \& Underwood LE (1994) Nutritional regulation of the insulin-like growth factors. Endocr Rev 15, 80-101.

5. Roberts CT, Owens JA, Sferruzzi-Perri AN, et al. (2008) Distinct actions of insulin-like growth factors (IGFs) on placental development and fetal growth: lessons from mice and guinea pigs. Placenta 29, Suppl. A, S42-S47.

6. Forbes K \& Westwood M (2008) The IGF axis and placental function. A mini review. Horm Res 69, 129-137.

7. Gargosky SE, Owens JA, Walton PE, et al. (1991) Administration of insulin-like growth factor-I, but not growth hormone, increases maternal weight gain in late pregnancy without affecting fetal or placental growth. $J$ Endocrinol 130, $395-400$

8. Jones JI \& Clemmons DR (1995) Insulin-like growth factors and their binding proteins: biological actions. Endocr Rev 16, $3-34$.

9. Sakai K, Iwashita M \& Takeda Y (1997) Profiles of insulin-like growth factor binding proteins and the protease activity in the maternal circulation and its local regulation between placenta and decidua. Endocr J 44, 409-417.

10. Skjaerbaek C, Frystyk J, Orskov H, et al. (2004) Free IGF-I, IGFBP-1, and binary complex of IGFBP-1 and IGF-I are increased during human pregnancy. Horm Res 62, 215-220.

11. Giudice LG, Farrell EM, Pham H, et al. (1990) Insulin-like growth factor binding proteins in maternal serum throughout gestation and in the puerperium: effects of a pregnancyassociated serum protease activity. $J$ Clin Endocrinol Metab 71, 806-816.

12. Olausson H, Lof M, Brismar K, et al. (2008) Longitudinal study of the maternal insulin-like growth factor system before, during and after pregnancy in relation to fetal and infant weight. Horm Res 69, 99-106.

13. Frystyk J, Hojlund K, Rasmussen K, et al. (2002) Development and clinical evaluation of a novel immunoassay for the binary complex of IGF-I and IGF-binding protein-1 in human serum. $J$ Clin Endocrinol Metab 87, 260-266.

14. Baxter R (1995) Insulin-like growth factor binding proteins as glucoregulators. Metabolism 44, 12-17.

15. Hall K, Hansson U, Lundin G, et al. (1986) Serum levels of somatomedins and somatomedin-binding protein in pregnant women with type 1 or gestational diabetes and their infants. $J$ Clin Endocrinol Metab 63, 1300-1306.

16. Caufriez A, Frankenne F, Hennen G, et al. (1993) Regulation of maternal IGF-I by placental GH in normal and abnormal human pregnancies. Am J Physiol Endocrinol Metab 265, E572-E577.

17. Boyne MS, Thame M, Bennett FI, et al. (2003) The relationship among circulating insulin-like growth factor (IGF)-I, IGFbinding proteins- 1 and -2 , and birth anthropometry: a prospective study. J Clin Endocrinol Metab 88, 1687-1691.

18. Clapp JE, Schmidt S, Paranjape A, et al. (2004) Maternal insulin-like growth factor-I levels (IGF-I) reflect placental mass and neonatal fat mass. Am J Obstetr Gynecol 190, 730-736.

19. Hills FA, English J \& Chard T (1996) Circulating levels of IGF-I and IGF-binding protein-1 throughout pregnancy: relation to birthweight and maternal weight. $J$ Endocrinol 148, 303-309.

20. Lukanova A, Lundin E, Zeleniuch-Jacquotte A, et al. (2004) Body mass index, circulating levels of sex-steroid hormones, IGF-I and IGF-binding protein-3: a cross-sectional study in healthy women. Eur J Endocrinol 150, 161-171. 
21. Jernström H \& Olsson H (1998) Insulin-like growth factor-1 in relation to adult weight and birth weight in healthy nulliparous women. Int J Gynecol Obstetr 62, 11-18.

22. Ahmed RL, Thomas W \& Schmitz KH (2007) Interactions between insulin, body fat, and insulin-like growth factor axis proteins. Cancer Epidemiol Biomarkers Prev 16, 593-597.

23. Baldwin S, Chung T, Rogers M, et al. (1993) Insulin-like growth factor-binding protein-1, glucose tolerance and fetal growth in human pregnancy. $J$ Endocrinol 136, 319-325.

24. Holmes RP, Holly JMP \& Soothill PW (2000) Maternal insulinlike growth factor binding protein-1, body mass index, and fetal growth. Arch Dis Child Fetal Neonatal Ed 82, F113-F117.

25. Lof M, Olausson H, Bostrom K, et al. (2005) Changes in basal metabolic rate during pregnancy in relation to changes in body weight and composition, cardiac output, insulin-like growth factor-I, thyroid hormones and in relation to fetal growth. Am J Clin Nutr 81, 678-685.

26. Lof M \& Forsum E (2006) Activity pattern and energy expenditure due to physical activity before and during pregnancy in healthy Swedish women. Br J Nutr 95, 296-302.

27. Lof $M \&$ Forsum $E$ (2004) Hydration of fat-free mass in healthy women with special reference to the effect of pregnancy. Am $J$ Clin Nutr 80, 960-965.

28. Forsum E, Lof M, Olausson H, et al. (2006) Maternal body composition in relation to infant birth weight and subcutaneous adipose tissue. Br J Nutr 96, 408-414.

29. Eriksson B, Lof M, Olausson H, et al. (2009) Body fat, insulin resistance, energy expenditure and serum concentrations of leptin, adiponectin and resistin before, during and after pregnancy in healthy Swedish women. Br J Nutr 103, 50-57.

30. Jorgensen C (1997) Fetometri och graviditetslängdbestämning (Fetometri and gestational age determination). In Obstetriskt ultraljud (Obstetric Ultrasound), pp. 37-44 [Svensk förening för obstetril och gynekologi: and Arbets- och referensgrupp för ultraljudsdiagnostik, editor]. Västerås: Västra Aros Tryckeri AB.

31. Niklasson A \& Karlberg P (1993) Weight-for-length model in newborn Swedish infants. Acta Paediatr 82, 333-339.

32. Bang P, Eriksson U, Sara V, et al. (1991) Comparison of acid ethanol extraction and acid gel filtration prior to IGF-I and IGF-II radioimmunoassays: improvements of determinations in acid ethanol extracts by the use of truncated IGF-I as radioligand. Acta Endocrinol 124, 620-629.

33. Póvoa G, Roovete A \& Hall K (1984) Cross-reaction of serum somatomedin-binding protein in a radioimmunoassay developed for somatomedin-binding protein isolated from human amniotic fluid. Acta Endocrinol 107, 563-570.

34. Ostlund I, Hanson U, Bjorklund A, et al. (2003) Maternal and fetal outcomes if gestational impaired glucose tolerance is not treated. Diabetes Care 26, 2107-2111.

35. Jansson T, Cetin I, Powell TL, et al. (2006) Placental transport and metabolism in fetal overgrowth - a workshop report. Placenta 27, Suppl. A, S109-S113.

36. Franks PW, Looker HC, Kobes S, et al. (2006) Gestational glucose tolerance and risk of type 2 diabetes in young Pima Indian offspring. Diabetes 55, 460-465. 